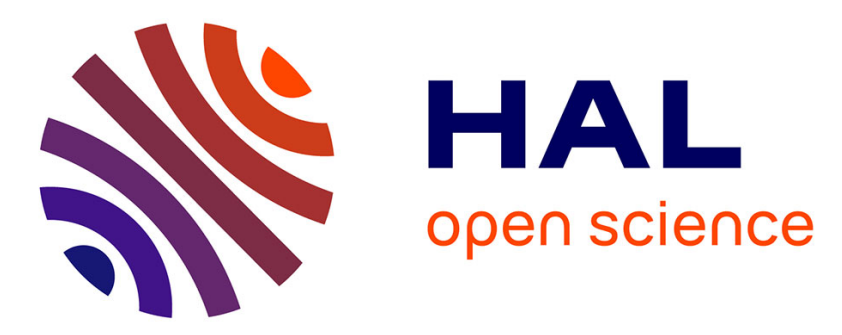

\title{
A European emotional investigation in the field of shoes design
}

\author{
Carole Bouchard, Fabrice Mantelet, Améziane Aoussat, Clara Solves, Juan
}

Carlos Gonzales, Kim Pearce, Shirley Coleman

\section{- To cite this version:}

Carole Bouchard, Fabrice Mantelet, Améziane Aoussat, Clara Solves, Juan Carlos Gonzales, et al.. A European emotional investigation in the field of shoes design. International Journal of Product Development, 2009, 7 (1/2), pp.3-27. 10.1504/IJPD.2009.022274 . hal-00874659

\section{HAL Id: hal-00874659 \\ https://hal.science/hal-00874659}

Submitted on 21 Oct 2013

HAL is a multi-disciplinary open access archive for the deposit and dissemination of scientific research documents, whether they are published or not. The documents may come from teaching and research institutions in France or abroad, or from public or private research centers.
L'archive ouverte pluridisciplinaire HAL, est destinée au dépôt et à la diffusion de documents scientifiques de niveau recherche, publiés ou non, émanant des établissements d'enseignement et de recherche français ou étrangers, des laboratoires publics ou privés. 


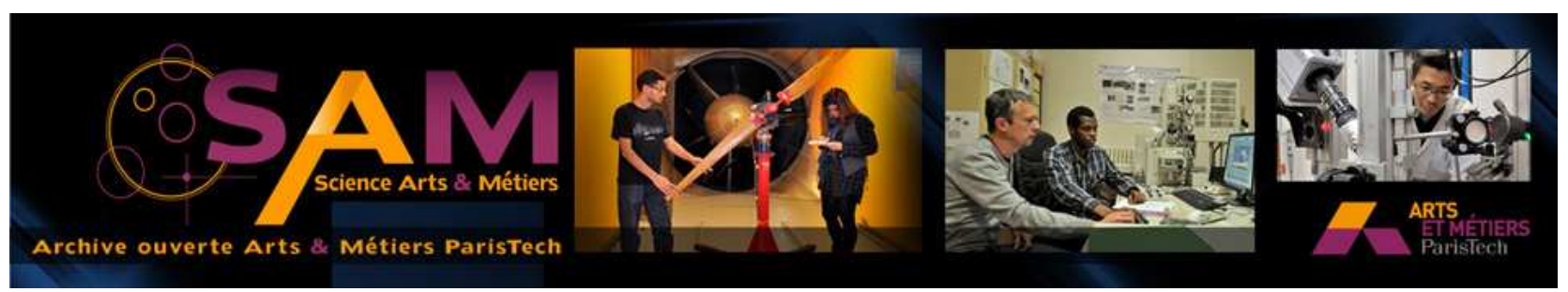

\section{Science Arts \& Métiers (SAM)}

is an open access repository that collects the work of Arts et Métiers ParisTech researchers and makes it freely available over the web where possible.

This is an author-deposited version published in: http://sam.ensam.eu

Handle ID: .http://hdl.handle.net/10985/7402

\section{To cite this version :}

Carole BOUCHARD, Fabrice MANTELET, Améziane AOUSSAT, Clara SOLVES, Juan Carlos GONZALES, Kim PEARCE, Shirley COLEMAN - A European emotional investigation in the field of shoes design - International Journal of Product Development - Vol. 7, n¹/2, p.3-27 - 2009 


\title{
A European emotional investigation in the field of shoes design
}

\section{Carole Bouchard ${ }^{*}$, Fabrice Mantelet, Améziane Aoussat}

Laboratory CPI-ENSAM, 151 Bd de 1[Hopital, 75013 Paris, France

E-mail : carole.bouchard@paris.ensam.fr

E-mail : fabrice.mantelet2@etudiants.ensam.fr

E-mail : améziane.aoussat@paris.ensam.fr

Phone: $0033144246378 \square$ Fax: 0033144246359

* Corresponding author

\section{Clara Solves, Juan Carlos Gonzales}

Instituto de Biomecanica de Valencia, Universidad Politécnica de Valencia (Edificio 9C) Camino de Vera s/n.

46022 Valencia. Spain.

Email: clara.solves@ibv.upv.es

Email: jcgonza@ibv.upv.es

Phone: $0034963879160 \square$ Fax: 0034963879169

\section{Kim Pearce, Shirley Coleman}

ISRU,

Stephenson Centre, Stephenson Building, University of Newcastle upon Tyne

Newcastle-upon-Tyne, NE1 7RU

E-mail: K.F.Pearce@newcastle.ac.uk

E-mail: Shirley.Coleman@newcastle.ac.uk

Phone: $001912228513 \square$ Fax: 001912227365

\begin{abstract}
In this paper we report on the results of a Kansei Engineering System study.

A methodology for the application of Kansei Engineering at a European level has been developed and validated in the field of shoes design by means of the development of experimental studies in two different phases of the product design : the information phase in the earliest stages of the design process and the generation and evaluation phase corresponding to the latest stages of the process.
\end{abstract}

Keywords: Kansei Engineering System (KES), Emotional Design, Conjoint Trends Analysis (CTA), Shoes design, Statistical Analysis.

Reference to this paper should be made as follows: Carole Bouchard, Fabrice Man,telet, Améziane Aoussat, Clara Solves, Juan Carlos Gonzales, Kim Pearce, Shirley Coleman (xxxx) A European emotional investigation in the 


\begin{abstract}
Author
field of shoes design $\square$ Int. J. Product Development, Vol. X, No. Y, pp.000 000 .

Biographical notes: Dr. Carole Bouchard is associate professor at the Ecole Nationale Supérieure des Arts et Métiers, France. Her research activities are centred on Design Watch Methods, Engineering Emotional Design, and Applied Creativity and Innovation.
\end{abstract}

Fabrice Mantelet is a postgraduate working on emotional design at the Ecole Nationale Supérieure des Arts et Métiers, France.

Prof. Améziane Aoussat is the head manager of the Laboratoire Conception de Produits et Innovation at the Ecole Nationale Supérieure des Arts et Métiers, France. His role is in the management of the overall research activities as well as industrial collaborations.

Ing. Clara Solves is a researcher of the Footwear Section at the Instituto de Biomecáncia de Valencia (Spain) and her activities are centred on emotional design methodologies.

Ing. Juan Carlos González is the coordinator of the Footwear Section at the Instituto de Biomecáncia de Valencia, Spain. His role is the coordination of research activities.

Dr Kim Pearce is a chartered statistician and senior statistician of the Industrial Statistics Research Unit, University of Newcastle. She specialises in the analysis of complex multivariate datasets and in the design of instruments for opinion surveys.

Dr Shirley Coleman is a chartered statistician and technical director of the Industrial Statistics Research Unit, University of Newcastle. She specialises in the interpretation of complex issues and their solution in terms of measurement and statistical analysis.

\title{
1. Introduction
}

The last decade reveals a strong orientation towards user centred design in research and industry. More recently, a new theme has appeared in design research in Europe, emphasizing the importance of emotion in the field of user-centred design [1] [2]. Beyond usability, positive emotional reactions are helpful in the understanding of the product and its use. Even if designers are conscious of the importance of working on the emotional dimension, often this is not taken into account. Designers integrate naturally and intuitively emotional attributes in their design but they are not able to assess precisely their effect. Human factors researchers begin to deal with emotions and to attempt to apply scientific method to search for understanding [3]. Evaluation in design becomes oriented towards emotions and constitutes a base for the generation of new designs.

In this paper, we will present the theoretical context in which Emotional Design and Kansei Engineering have been developed, then we will describe the scientific and industrial scenario in which the Kensys project takes place, before talking about 
Title

experiments in the specific sector of shoe design. The discussion opens new perspectives in emotional design and Kansei engineering.

\section{Theoretical background}

\subsection{Context}

The design process is made up of many cycles containing an informative phase, a generative phase and an evaluative and decision-making phase [4]. The informative phase corresponds to the integration of many categories of information that will be gradually formalized as design solutions. The generative phase consists of the formation of new ideas and new solutions under the form of more and more concrete models. The evaluation and decision-making phase concerns the choice of the right solutions to be developed by an evaluation and deduction process.

In the design process, the efficacy of each phase will influence the whole process and the three phases should be of equal value to achieve optimal results. Optimization prospects in design lead to a formalization and a computerization of the earliest phase in a proactive way. It means that the generative and evaluative phases tend to become more and more interlinked. There is a recent concern in Europe under the name of Emotional Design (ED), which is more centred on the evaluation phases. On the other hand Kansei Engineering (KE), being a more mature subject in Japan, integrates evaluation results for the generation phase in a pro-active way. KE differs from ED in the way that it leads to technology. Due to the specificity of the activity of the industrial designer linked with emotions, it is difficult to develop Computer Aided Design (CAD) tools for the earliest phases of the design process where the design information is still vague [5]. KE methods aim to handle peoples $\sqsubset$ emotional analysis to elaborate new CAD Tools for ED.

Both concepts of ED and KE are mainly based on an initial evaluation through the semantic analysis method developed by Osgood [6], which is a potential evaluation model determined by the visual evaluation of product images helping designers to understand their own communication models [7].

\subsection{Concepts}

\subsubsection{Emotional Design}

The concept of Emotional Design was initially mainly diffused in the worldwide design research community by Norman [2], Green and Jordan [3], and through the Design and emotion conference [8]. Emotional Design is a common research field involving both designers and human factors researchers. Following the method of semantic evaluation, studies have mainly taken place in Europe [6] [7] [8] [9] [10] [11] [12] [13] [14]. Initially they had only to do with semantic analysis; today they tend to integrate explicitly the emotional analysis with the semantic one [15] [16] [17] [18]. Notions like personality are still controversial in the context of product design [19].

\subsubsection{Kansei Engineering}

Kansei technology was derived in Hiroshima University about 30 years ago by Mitsuo Nagamachi [20], subsequently providing many successful results in industry. KE 
Author

is used to determine which emotional attributes elicit particular subjective reactions from users. This allows the designing of products using the attributes which elicit the desired reactions. Evaluation results are integrated in the KE process through a pro-active approach.

Although many studies have followed a semantic approach ([21] [22] [23] [24] [25] [26] [27] [28] [29]), in order to perform KE, authors suggest that new behavioural and physiological measurements should be incorporated [30].

\section{Problem statement}

In the following part of this paper, we will focus on the development of a Kansei Engineering System (KES) validated in the sector of shoe design. This is the focus of the Kensys project. In Europe, few studies mention a KES fully implemented into small enterprises who do not have the skilled human resource to apply this kind of method on their own. Even though much has been written about KES, few have considered the following questions: the European scope obtained from the participation of different countries in the study, the innovation ability resultant from the consideration not only of the evaluative and generative phases but also of the informative phase and the complementarity of the emotional and the semantic components. This gives uniqueness to the approach undertaken in the Kensys Project.

\subsection{Managing a European study considering the lexical and cultural differences}

Most of the time the target markets related to industrial design involve different countries. One challenge for a cross-European study is the cultural differences between regions. Translating descriptive words across languages is also difficult $[31,32]$. In the present study a different set of Kansei words has had to be collected in each participating country, and different design rules have consequently been developed. Considering differences between countries is a major difficulty of the research.

\subsection{Enriching the input data of the KES and ensuring the innovation ability of the KES}

KE approaches are sometimes criticized because the databases they use are only built with existing products and therefore the innovation opportunities are reduced because new properties can not be drawn from these data [13]. In fact, KES is centred on the evaluative and generative phases (evaluation of the image of a designed stimulus and generation of design candidates with prediction of the consuming behaviour) while less attention has been paid on the informative phase found in the traditional design process. Many studies show the importance of the informative phase in the traditional design process [33] [34] [35], where the novelty of the design solutions depends mainly on the use of external influences, being a base for idea generation and mental representation. The trend factor, in particular, plays a major role in the generation of new ideas and new solutions. In this paper, we propose the integration of the Conjoint Trends Analysis (CTA) Method in the traditional KES [36][37]. Through the use of this method, the purpose is to enrich the input data with trend cards in the products design elements database. Trend cards are iconic compositions able to communicate a homogeneous 
ambience both in terms of styles from various domains of influence and sociological values.

Figure 1 Trendcard and form-colours-texture pallets for Pastel luxury

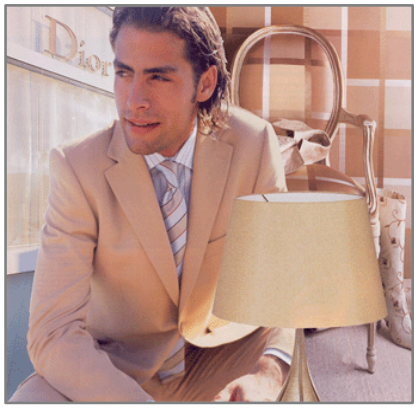

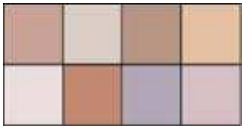

Colours

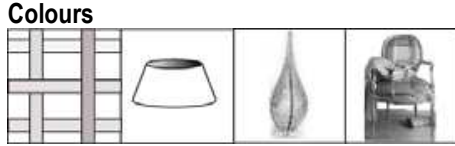

Forms

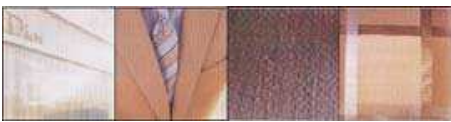

Texture
Luminous atmosphere with shades of warm beiges, greys and white.

Straight horizontal lines, oblique and mainly vertical refined by floral curves and empire lines.

Delicate and sensitive textures, silky, with gilt touch, subtle sophisticated fabrics.

Specific design attributes are extracted from palettes, hence harmonies are picked and transferred. Trend cards offer quite an exhaustive representation of the references usually used by the designers. They reinforce the semiotic coherence between consumers $\square$ values and products attributes, aesthetics and attractiveness, enriching the databases with dynamic data closer to the market. In the CTA method, trend cards are built on the base of Rokeach values [38] : designers establish coherent relationships between the conceptual space (values, functions) and product attributes. Finally two steps were added to the traditional KES process in the following experiments : the integration of trend cards produced by the designers and their evaluation by the users.

\subsection{Introducing real emotional analysis to complement the semantic analysis}

In the literature, ED and KE refer mainly to the semantic differential approach. However, recent studies turn one's attention to the introduction of real emotions to complement the semantic analysis [39] [15] [16] [30] [18]. The difficulty lies in the choice of the appropriate emotions and of the relevant manner to assess them in a design context. Three approaches can be found which are physiological (sanguine volume, cardiac rhythm, electro-dermal activity and breathing frequency [40] [41]), behavioural (facial mimics, voice intonation [42] [43] [44]) or cognitive. The latter is based on measurement scales allowing us to assess emotional feelings.

The emotions involved in the specific context of product evaluation like well being or serenity (secondary emotions) are difficult to measure in physiological or behavioural ways. Therefore the following experiments will be based on cognitive measurements based on questions with an attitude scale and the Self Assessment Manikin (SAM) [41] of Lang. The emotions used in a questionnaire can be selected from the list of 50 emotions proposed by the Psychology Department of the Geneva University, choosing the most discriminating ones in the case of visual stimuli through pilot tests [39]. These emotions are specified by verbal data although the cognitive emotional analysis is not systematically done with lexical data [15] [16] because of the difficulty to express rigorously the subtlety of certain emotions by means of visual icons. 
Author

\section{Case studies}

The study involved the utilisation of KE methodologies to the all-day man footwear at a European level, involving three different countries (France, Spain and UK). The respective studies have been developed under coordinated environments in order to follow the same procedures and to deal with the same parameters.

The objective of the work developed has been the integration of the users $\square$ preferences about the product in terms of emotional and perceptual requirements by conducting two experimental studies corresponding to different phases of the product design process : the information phase and the evaluation phase.

The information phase is a stage for idea generation; the user $s$ integration in this phase involves the evaluation of conceptualized information. This has been developed through the Conjoint Trends Analysis Method which aimed to define trend cards related to shoes design. These trend cards were evaluated by the users according to both semantic and emotional analysis in England, France and Spain. Kansei design rules have not been obtained in this phase due to the complexity of obtaining an experiment sample. In the evaluation phase the ideas are formalized into design solutions, so the Kansei study was developed on the basis of existing design proposals found in the market. The semantic concepts that describe the product image and the design rules that relate the design features with the user $s$ emotional framework represented by means of these semantic concepts have been obtained.

A KES was built from the user preferences to predict on one hand the perception generated by the product and on the other hand the design elements that are most appropriate for transmitting an idea previously established by the manufacturer.

\subsection{Methods}

\subsubsection{Early emotional evaluation in shoes design : information phase}

Three main hypotheses originated from the state of the art related to the early emotional evaluation. The first was that the trend cards, being evaluated by the users in the early design process, can provide further information for the database of the KES. The second one is that some rules can be established from this evaluation between users values, their preferences and emotional reaction in front of trend cards. These hypotheses led us to use specific instruments that are described in the following sections.

\section{Protocol and procedure}

This first experiment aimed at studying a new way of users integration in KES. It was centred on the emotional evaluation of atmospheres relating to trend cards in France, Spain and England. The experimental protocol was based on a questionnaire method in the sector of shoe design, involving 82 European subjects (see Table 1). It integrated values in order to examine their potential predictivity on the emotions and semantics preferences, and further choose design elements. The results made up a base for establishing further design rules for a KES. This approach included the following steps :

1 Definition of the lexical corpus (emotions, semantic adjectives, values)

2 Definition of the expected results (users free adjectives, trend cards semantic analysis, values analysis)

3 Definition and development of the questionnaires (Web and paper versions)

4 Data gathering 
Title

5 Data analysis (Principal Component Analysis, Regression analysis, Sorting)

6 Interpretation of the results

Table 1 Users sample

\begin{tabular}{ccccc}
\hline Gender & & France & Spain & England \\
\hline $\boldsymbol{M}$ & 36 & 24 & 6 \\
& $\boldsymbol{F}$ & 20 & - & 6 \\
\hline
\end{tabular}

\section{Instruments}

The instrument was a questionnaire, including the following elements:

- 15 Trend cards to assess

- $\quad$ List of 10 emotional reactions

- $\quad$ List of 18 personal behavioural values

cards

- Visual Analog Scale (VAS) to measure the valence and intensity in front

- $\quad$ Scales with a 5 point Likert range

The questionnaire included closed questions and was distributed under both forms of paper and web. The questions were centred on users identity, human values, preferences, and the semantic and emotional quotation. The scale used for the evaluation was a 5 degree Likert scale. The expected result was the emotional and semantic evaluation of the trend cards, and its relation with values and preferences.

Trend cards

15 Trend cards were produced by the designers, illustrating 15 different atmospheres like (1) White Organic, (2) Pastel luxury, (3) Graphic elegance, (4) Lord, (5) Pop chic, (6) Essential minimal, (7) Graphic elegance, (8) Quirky pop, (9) Cyborg, (10) Modern Heritage, (11) Roots, (12) Cyber pop, (13 Zen air), (14) Neo baroque and (15) bio organic (see figure 7). The proposed trend cards correspond to middle and up market products.

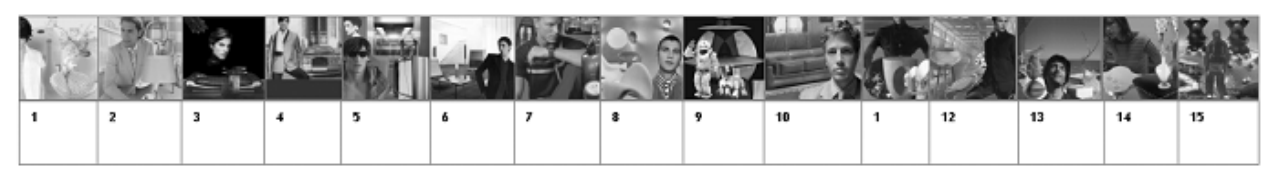

Figure 2 Trend cards sample

\section{Emotions}

The retained emotions were : Amused, Astonished, Hesitant, Ill at ease, Inspired, Puzzled, Serene, Stimulated, Touched. 
Author

\section{Values}

The following list of behavioural values established by Rokeach was used in this first experiment : ambitious, serious, capable, pure, courageous, playful, indulgent, obedient, honest, imaginative, independent, intellectual, logical, loving, docile, polite, responsible, and self controlled. The use of behavioural values instead of terminal values is due to their more concrete and understandable character for the users.

\subsubsection{Emotional evaluation in shoes design: generation and evaluation phase}

The second approach to the design process was focused on the analysis of users $\square$ perception after the detailed design of the product. Kansei Engineering has been applied for translating and capturing the mental images, perceptions, sensations and preferences of the consumer for the design elements that compose the product. Product Semantics have been used in the study to evaluate how products are perceived.

\section{Protocol and procedure}

The first stage consisted of the application of Product Semantics for analysing the global perception of the product by the consumers. The process began by compiling from several sources (final users, experts and promotion channels) the terms (Kansei words) used to describe perception regarding all-day man footwear. The words were then grouped and filtered in order to get a manageable set of concepts.

This processed information made up the Reduced Semantic Universe (RSU) and constituted the starting point for obtaining the Semantic Space of the product. The terms were evaluated by respondents for each product in the sample. The semantic spaces for all-day man footwear were obtained from the evaluation results by applying factor analysis.

Once the semantic structure of the all-day man footwear was elicited, the Kansei Engineering technique was applied to obtain the design rules of the product by exploring the user emotional reactions and relating them to the design features.

The procedure established to define the design elements for all-day man footwear was innovative, since it considered both designers and users criteria. Firstly, the group of designers defined and weighted the design elements and associated categories and secondly, users selected the final list depending on their preference for the product.

To extract the effects of the design elements on the consumers $\square$ reaction, a representative sample of products was selected, trying to obtain a balanced combination of the design categories. To do this, a large number (approximately 360) product images were gathered and classified utilising the 10 design elements finally selected. The complexity of finding a high number of products with particular combinations of design elements involved working with product images and therefore the selection of the design elements was adapted to this circumstance. The methodology chosen for the selection of the final product sample was a hybrid method incorporating (i) the selection of a sub-set of samples using a designed experiment array with the 5 most important design elements and (ii) the selection of a complementary product sample from the product universe trying to represent as well as possible the variability of the other design elements.

During the Kansei evaluations, samples of users evaluated each product using a set of semantic axes (see Table 2). As the assessed response categories occur on an ordinal scale it was appropriate to use as the statistical modelling technique, ordinal logistic 
Title

regression. This procedure has been widely documented in the past [45] [46] [47] [48] [49] [50].

Table 2 Kansei evaluation sessions

\begin{tabular}{r|l|l}
\hline $\begin{array}{l}\text { Sessions } \\
\text { description: }\end{array}$ & Spain & Britain \\
\hline Place & University of Valencia & $\begin{array}{l}\text { University of Newcastle upon Tyne and the } \\
\text { University of Strathclyde, the facilities of the } \\
\text { Competitive Scotland unit }\end{array}$ \\
\hline Product sample size & 99 shoe images & $\begin{array}{l}44 \text { users in total, number of responses for } \\
\text { each image varies }\end{array}$ \\
\hline $\begin{array}{r}\text { Search perception } \\
\text { method }\end{array}$ & Semantic Differential Scales corresponding to the respective semantic spaces \\
\hline
\end{tabular}

\section{Instruments}

Questionnaires with five point semantic differential scales were used both for the semantic and the kansei evaluations. A semantic scale consists of two opposing adjectives or concepts separated by a scale. For the Kansei evaluation, the labels corresponding to each one of the semantic axes were used to create a similar set of semantic differential scales to those in the previous semantic evaluation. The semanticscale concept is displayed below:

Contemporary

\begin{tabular}{||c||l||l||l||l||}
\hline 1 & 2 & 3 & 4 & 5 \\
\hline \hline$x$ & & & & \\
\hline
\end{tabular}

Not Contemporary

\subsection{Results}

\subsubsection{Early emotional evaluation in shoes design : information phase}

\section{Correlations related to emotions}

The results of the emotional evaluation of the trend cards revealed that the emotion astonished is representative of the most innovative ambiences. In the three countries, it is linked to complementary emotions like puzzled and amused. These feelings are correlated in England with ill at ease, and in Spain with enthusiastic and touched respectively. In fact in the specific context of this study, novelty provoked more enthusiasm in Spain, where the population leaned more toward the friendly side of the ambiences (especially Trendcard 9 Cyborg). In France and in England enthusiasm is closer to serene and inspired. In France novelty had no impact on the polarity of the emotions. 
Author

\section{Emotional responses}

Figure 3 PCA for France, Spain and England respectively
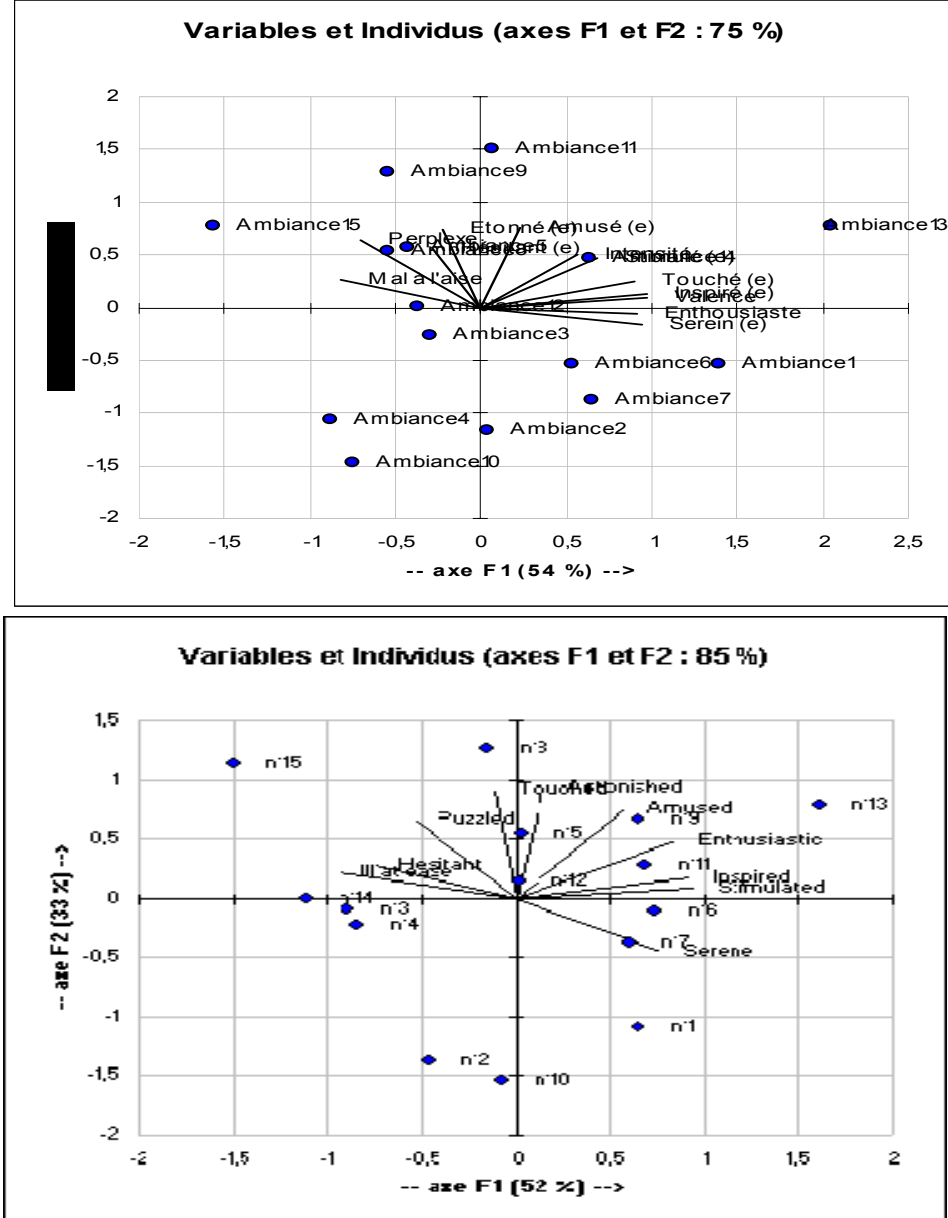

Variables et Individus (axes F1 et F2 : $75 \%$ )

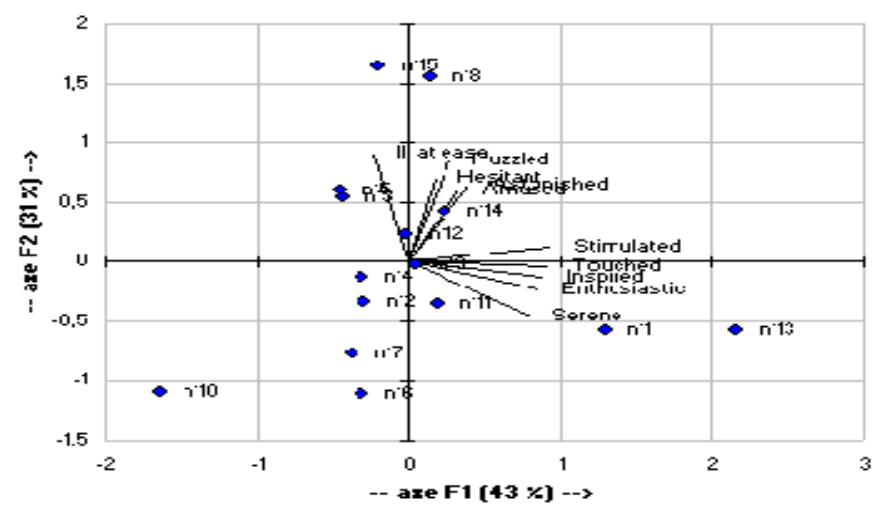


Considering the results of the PCA in the 3 countries, we can observe similarities for certain ambiences and differences for other ones. These differences can be due to the specific cultural variations and to the maturity dissemination level of each trend in each country. Similarities can mainly be illustrated by the common positive reaction with ambience 13 in the three countries and the negative one with ambience 15 which was related to ill at ease and puzzled. Ambience 13 provoked the most enthusiastic and stimulating reaction, generating the greatest inspiration. Ambience 15 reflected strangeness ; it was closed to ill at ease, very far from serenity, and the most rejected in the three countries.

A great variability in the emotional reaction appeared especially in relation with the more or less innovative perception of the different ambiences in the different countries. A seen previously, the perception of innovation is mainly underlined by the emotion astonished (as generally measured on the F2 axis). Ambience 11 was considered as innovative only in France. The variability is underlined by the emotional reactions serene in England, inspired and enthusiastic in Spain, and amused and astonished in France. Ambience 8 is considered as very innovative (except in France) and rather disturbing (except in Spain). Finally the most and the less astonishing ambiences are different in the three countries (the most : 8 in France, 15 in Spain and 5 in England; the less : 15 in France, 4 in Spain and 3 in England).

\section{Effect of values on emotional responses and semantic adjectives}

The effect of the behavioural values on the emotional responses is clear for each ambience. Numerous significant relationships were found between emotional responses and the behavioural values which people aspire to.

Table 3 Significance of the link between end values words and preferred trend cards for France and Spain : only significant results $(p=<0,05)$ have been reported here

\begin{tabular}{|c|c|c|c|}
\hline Trend cards & Emotional response & $\begin{array}{c}\text { Significance of ideal } \\
\text { behavioural effect } \\
\text { France }\end{array}$ & $\begin{array}{c}\text { Significance of ideal } \\
\text { behavioural effect Spain }\end{array}$ \\
\hline 1 White organic & Enthusiastic & $\mathrm{x}$ & \\
\hline 2 Pastel luxury & Amused & $\mathrm{x}$ & $\mathrm{x}$ \\
\hline 3 Modern luxury & Inspired & $\mathrm{x}$ & \\
\hline 4 Lord & Enthusiastic & $\mathrm{x}$ & \\
\hline 5 Pop chic & $\begin{array}{c}\text { Enthusiastic, Inspired, } \\
\text { Touched } \\
\text { Astonished }\end{array}$ & $\mathrm{x}$ & $\mathrm{x}$ \\
\hline 6 Essential minimal & Puzzled, Touched & $\mathrm{x}$ & \\
\hline 7 Graphic elegance & Hesitant, Ill at ease & $\mathrm{x}$ & \\
\hline 8 Quirky pop & $\begin{array}{c}\text { Enthusiastic, Inspired } \\
\text { Stimulated } \\
\text { Hesitant }\end{array}$ & $\begin{array}{l}\mathrm{x} \\
\mathrm{x}\end{array}$ & $\begin{array}{l}x \\
x\end{array}$ \\
\hline
\end{tabular}


Author

\begin{tabular}{c|c|c|c}
\hline 9 Cyborg & $\begin{array}{c}\text { Enthusiastic, Inspired, } \\
\text { Stimulated, Touched, } \\
\text { Puzzled }\end{array}$ & $\mathrm{x}$ & $\mathrm{x}$ \\
\hline 10 Modern heritage & Serene & & $\mathrm{x}$ \\
\hline 11 Roots & $\begin{array}{c}\text { Enthusiastic, Ill at ease, } \\
\text { Serene }\end{array}$ & $\mathrm{x}$ & $\mathrm{x}$ \\
\hline 12 Cyber pop & $\begin{array}{c}\text { Amused, Puzzled } \\
\text { Enthusiastic }\end{array}$ & $\mathrm{x}$ & \\
\hline 13 Zen air & $\begin{array}{c}\text { Enthusiastic, Ill at ease, } \\
\text { Inspired, Serene, } \\
\text { Stimulated }\end{array}$ & $\mathrm{x}$ & $\mathrm{x}$ \\
\hline 14 Neo baroque & $\begin{array}{c}\text { Amused, Enthusiastic, } \\
\text { Stimulated } \\
\text { Astonished }\end{array}$ & & $\mathrm{x}$ \\
\hline 15 Bio organic & Hesitant \\
Amused & $\mathrm{x}$ & \\
\hline
\end{tabular}

These relationships between behavioural values and emotional responses were applied to every trend card except the trend card (10) Modern heritage in France, and the trend cards (1) White organic, (3) Modern luxury, (4) Lord, (6) Essential minimal, (7) Graphic elegance, and (13) Zen air in Spain.

An additional relation was studied in order to explore the effect of the importance given to the projected image on the trend cards preferences. A significant relation was found for the trend card 7 Graphic elegance.

These results confirm that the behavioural values have a predictive effect which is more visible through the French results. The differences between the three countries can come from the cultural variability acting on (i) the different correlations between the emotions or (ii) the ideal behavioural values people aspire to in different countries. The correlation analysis showed that the relations between the different emotions in the three countries have a common core, however there are divergences.

For instance, if we consider the common core, astonished, it is linked to the two other complementary emotions amused or puzzled. Inspired corresponds to the most positive pole including other emotions like enthusiastic, serene and stimulated. Ill at ease characterizes the most negative emotion which is positively linked to puzzled and negatively to serene.

On the other hand, there are some differences in the emotional responses too. England and in France, amused is only correlated with astonished. In Spain it is firstly correlated to enthusiastic, then astonished, touched and the other emotions representing the positive pole : inspired and stimulated. Novelty seems to have a more positive and strong impact for the Spanish population. Enthusiastic is not correlated with stimulated in France, as in Spain and in England. It is closer to serene. In Spain it is not correlated with touched, as in the two other countries. In Spain there is an additional correlation between astonished and touched or enthusiastic, and in England between astonished and ill at ease.

\subsubsection{Emotional evaluation in shoe design: generation and evaluation phase}




\section{Title}

The development of the Kansei methodology in the latest stages of the design process has provided different results directly applicable in the field of footwear and a set of procedures that can be also applied in other sectors.

\section{Product Semantics}

After applying Factor Analysis to the results obtained from the application of Product Semantics, the semantic spaces corresponding to all-day man footwear $\square$ in France, Spain and UK were obtained.

Table 4 Semantic Space for all-day man footwear

\begin{tabular}{|c|c|c|}
\hline $\begin{array}{c}\text { Spanish Semantic Space } \\
\text { ( } 7 \text { axes }) \\
\end{array}$ & $\begin{array}{c}\text { English Semantic Space } \\
(8 \text { axes })\end{array}$ & $\begin{array}{c}\text { French Semantic Space } \\
\text { (4 axes) }\end{array}$ \\
\hline MODERN-INNOVATIVE & CONTEMPORARY/ORIGINAL & AVANT-GARDE \\
\hline ELEGANT-WELL-DRESSED & CASUAL & COMFORTABLE \\
\hline COMFORTABLE-PRACTICAL & ATTRACTIVE/TASTEFUL & TRADITIONAL \\
\hline SOBER-CLASSIC & FASHIONABLE & CHIC \\
\hline $\begin{array}{l}\text { GOOD QUALITY-WELL } \\
\text { FINISHED } \\
\end{array}$ & COMFORTABLE & \\
\hline UP-TO-DATE & HARD WEARING/PRACTICAL & \\
\hline \multirow[t]{2}{*}{ CASUAL-SPORTING } & EASY/CONVENIENT & \\
\hline & EXPENSIVE/GOOD QUALITY & \\
\hline $60.32 \%$ variance explained & $61.6 \%$ variance explained & $85.7 \%$ variance explained \\
\hline
\end{tabular}

Each axis is formed by a set of terms from the RSU which are those terms more correlated to the concept. The Figure below shows the loadings of the terms from the Spanish universe in the Modern-Innovative and Elegant-Well dressed axes.

Figure 4 Loadings of the terms from the Spanish universe in the Modern-Innovative and Elegant-Well dressed axes 
Author

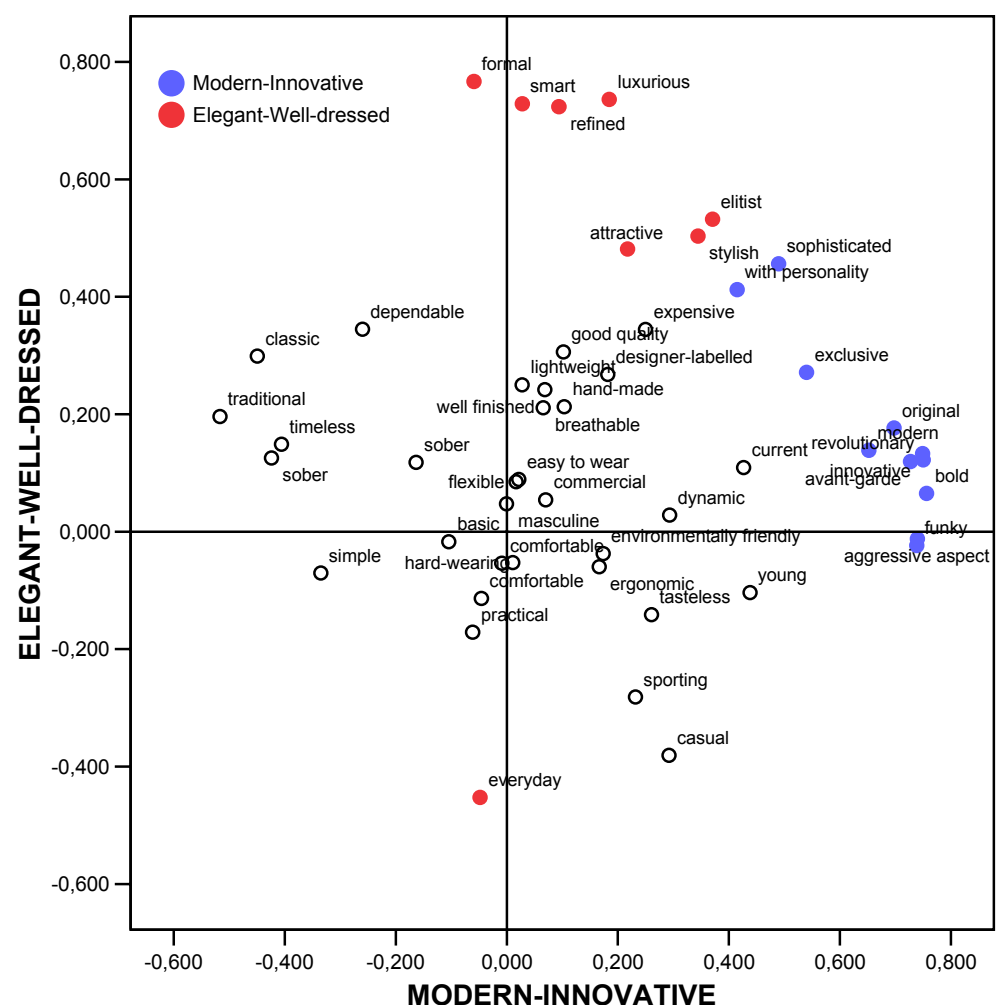

These axes constitute the basis for analysis of the users $\square$ perception generated by a particular product. We can thus establish comparisons between different design proposals. For example, in the Figure below, the perception elicited by two products in Spain is compared.

Figure 5 Comparison of the perception elicited by two products in Spain

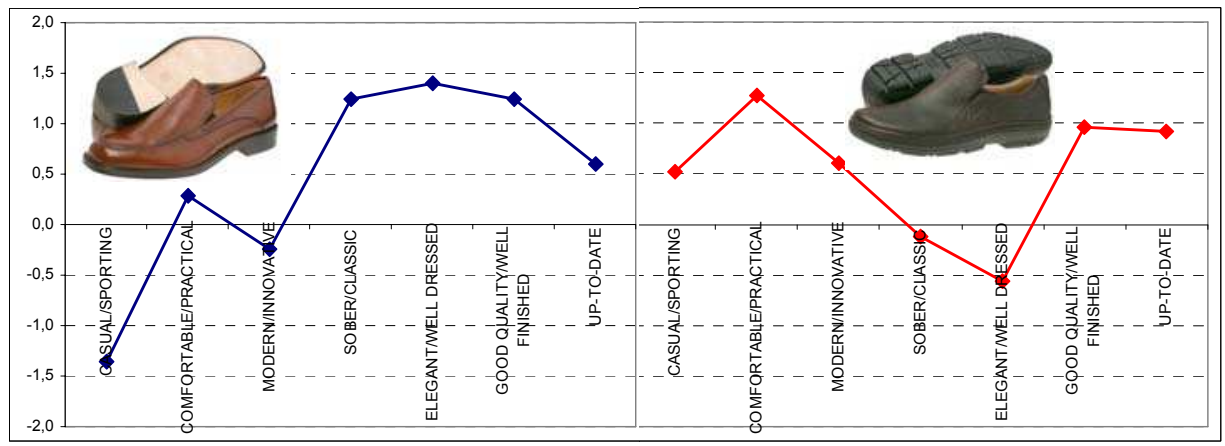

The design rules obtained from the Kansei methodology will explain the reasons of the differences in the users $\square$ perception.

\section{Kansei Engineering}


After obtaining the semantic concepts to characterize the product perception, design rules were defined by application of Kansei Engineering. These rules relate the design elements of the product to the semantic axes previously obtained.

\section{Design elements}

The design elements and their corresponding categories are used to describe the different product characteristics that produce positive, neutral and negative responses from the consumer. Due to the problems associated with describing all of the product features in perfect detail, the design elements merely summarize the most important characteristics that provide the product with its identity and appearance.

The following table shows the design elements finally obtained for all-day man footwear.

Table 5 Design elements for all-day man footwear

\begin{tabular}{c|c|c}
\hline Component & Design Element & Categories \\
\hline Toe Box & Last Wideness & Loose/ Tight \\
\hline & Top Profile & Square/Rounded \\
\hline \multirow{2}{*}{ The Upper } & Material & Leather/ Nubuck, Suede, Split \\
& Colour & Dark/Light \\
\cline { 2 - 3 } & Seams distribution & Plain Toe/ Moccasin/ Longitudinal/Straight-winged/ Sporting \\
\cline { 2 - 3 } & Collars & Without Collar/ Reinforced Collar/ Bagged and foam filled \\
\hline Fastenings & Fastenings & With Fastening/ Without Fastening \\
\hline Sole & Sole type & Soft-flat/ Angular \\
\hline & Sole Material & Leather/Synthetic \\
\cline { 2 - 3 } & Method of Application & Cemented-moulded/Welted (sole stitched on) \\
\hline
\end{tabular}

These design elements are common for the different countries and they represent the product parameters that will contribute to the users $\square$ emotional response.

\section{Design rules}

One ordinal logistic regression model was generated for each English and Spanish semantic axis for the prediction of each characteristic. All of the design elements were considered as potential predictors and each final model was made up of those elements whose estimated coefficients were significantly different from zero. The aim of the ordinal logistic regression was to :

- $\quad$ identify which design features had most influence on each semantic scale

- determine which levels of each important design feature elicited a positive response on the semantic scale.

- determine whether a predictive model could be produced for each semantic axis capable of predicting the score which would be given to a shoe based on the design features in the model.

The predictive ability of the models is given by the Kendall $\mathrm{s}$ Tau-a, which has a maximum value of 1 . Larger values indicate better predictive ability. The table below shows the values obtained for the models. 
Author

Table 6 Kendall $\varsigma$ Tau for Spain and England

\begin{tabular}{cccc}
\hline UK Semantic Axes & $\begin{array}{c}\text { Kendalls } \\
\text { Tau }\end{array}$ & Spanish Semantic Axes & $\begin{array}{c}\text { Kendall } \mathbf{s} \\
\text { Tau }\end{array}$ \\
Casual & 0.34 & Casual-Sporting & 0.43 \\
Contemporary- Original & 0.21 & Modern-Innovative & 0.27 \\
Attractive - Tasteful & 0.14 & Elegant $\square$ Well Dressed & 0.41 \\
Fashionable & 0.20 & Sober-Classic & 0.34 \\
Practical - Hardwearing & 0.24 & Comfortable-Practical & 0.28 \\
Comfortable & 0.26 & Good Quality- Well finished & 0.12 \\
Easy - Convenient & 0.27 & Up-To-Date & 0.18 \\
Expensive $\square$ Good Quality & 0.18 & & \\
\hline
\end{tabular}

Generally the majority of the models had some limited predictive ability (Kendal $\$$ Tau-a $<0.5$ ) based on the factors in the model. We can conclude that models with strong predictive ability have not been produced. Analysing the results, it was found that in the English data the models for Casual and in the Spanish data the model for CasualSporting were the best models as regards the predictive ability. These are possibly the models where respondents have a clear idea of what they believe constitute a practical or a casual shoe.

The models with the lowest predictive ability may correspond to concepts that users found more difficult to form an opinion on based on images.

The design features found to be significantly influencing the consumers $\square$ perception for each of the semantic scales are shown in Table 9 (UK Semantic Axes) and 10 (Spanish Semantic Axes). The design elements with the highest coefficients in the logistic regression models are highlighted (the colour key is shown at the bottom of the table). Blank cells indicate non significant design elements in the models.

Table 7 Design features significantly influencing the consumers $\square$ perception in UK

Key: Coefficient greater than 1

Coefficient between $0,7-1$

Coefficient between $0,4-0,7$

Coefficient smaller than 0,4

\begin{tabular}{|c|c|c|c|c|c|c|c|c|}
\hline UK Semantic Axes & $\begin{array}{l}\overline{\widetilde{J}} \\
\overline{\widetilde{J}} \\
\tilde{U}\end{array}$ & 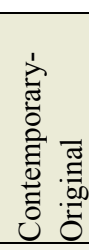 & 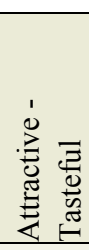 & 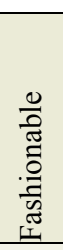 & 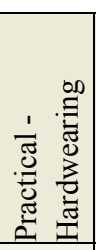 & 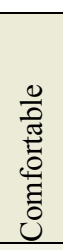 & 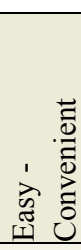 & 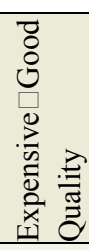 \\
\hline \multicolumn{9}{|l|}{ Design Factors } \\
\hline \multicolumn{9}{|l|}{ Top Profile } \\
\hline \multicolumn{9}{|l|}{ Material } \\
\hline \multicolumn{9}{|l|}{ Colour } \\
\hline \multicolumn{9}{|l|}{ Fastening } \\
\hline \multicolumn{9}{|l|}{ Sole Type } \\
\hline \multicolumn{9}{|l|}{ Sole Material } \\
\hline \multicolumn{9}{|l|}{ Seams Distribution } \\
\hline Last Width & & & & & & & & \\
\hline
\end{tabular}


Title

\begin{tabular}{|l|l|l|l|l|l|l|l|l|}
\hline Method of Application & & & & & & & & \\
\hline Collars & & & & & & & & \\
\hline
\end{tabular}

Table 8 Design features significantly influencing the consumers $\square$ perception in Spain

\begin{tabular}{|c|c|c|c|c|c|c|c|}
\hline Spanish Semantic Axes & 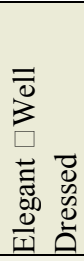 & 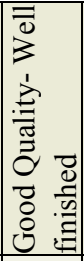 & 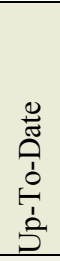 & 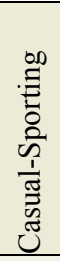 & 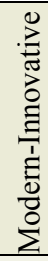 & $\begin{array}{l}0 \\
0 \\
0 \\
0 \\
0 \\
1 \\
\frac{1}{0} \\
0 \\
0 \\
0\end{array}$ & 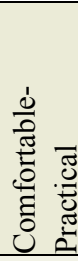 \\
\hline \multicolumn{8}{|l|}{ Design Factors } \\
\hline \multicolumn{8}{|l|}{ Top Profile } \\
\hline \multicolumn{8}{|l|}{ Material } \\
\hline \multicolumn{8}{|l|}{ Colour } \\
\hline \multicolumn{8}{|l|}{ Fastening } \\
\hline \multicolumn{8}{|l|}{ Sole Type } \\
\hline \multicolumn{8}{|l|}{ Sole Material } \\
\hline \multicolumn{8}{|l|}{ Seams Distribution } \\
\hline \multicolumn{8}{|l|}{ Last Width } \\
\hline \multicolumn{8}{|l|}{ Method of Application } \\
\hline Collars & & & & & & & \\
\hline
\end{tabular}

\section{Discussion}

The results obtained from the application of the Trends Analysis Methods could be considered as a conceptual approach to the user requirements as regards the earlier stages of the process of product development. Results from the application of Kansei Engineering in the generation and evaluation phase provide design solutions that can be used to validate products developed.

\subsection{Early emotional evaluation in shoe design : information phase}

In conclusion, we can recognize important emotional effects by way of the users evaluation of the trend cards in France, Spain and England.

The first analysis showed that the preferences between the different trend cards vary according to the three countries. Even if some trend cards reveal the same position on the preferences scale, we can find variability especially on the following trend cards : White Organic, Pastel luxury, Pop Chic, Quirky Pop, Cyborg and Zen air.

A comparison with the results of the PCA reveals that the preferred ambiences are characterized by the emotions enthusiastic, serene, stimulated, inspired, amused and touched (except in Spain where touched it closer to puzzled and astonished).

In this study, relationships were found between trend cards preferences and behavioural values. These findings show that the intended users behavioural values can help in predicting preferences for new designs. On the other hand, the observed 
Author

relationships were not very significant for all trend cards (4/15). This does not bring into question the predictive potential of behavioural values. Indeed the ranking of the different trend cards by preferences can correspond to very homogeneous or very mixed repartitions. The clearest repartition corresponds to the best significance with the trend cards 1 White organic, 15 Bio organic, 13 Zen air and 10 Modern heritage. Oppositely, certain trend cards led to different reactions according to respondents. The related preference quotations are distributed along the whole scale without any dominance of one rank. We can conclude that the significance of the relationships between trend card preferences and behavioural values is confirmed, and appears in the case where the preferences are clearly and homogeneously expressed.

Concerning the effect of behavioural values on the emotional reactions for each ambience, numerous significant relationships were found especially in France. The regression analysis showed the effect of the behavioural values on the emotional reactions for the whole trend cards sample in France and 8/15 trend cards in Spain. The difference between the significance in the three countries could be due in part to the fact that the trend cards were built on the base of French input data, more sensible for a French public. So we can suppose that the predictive potential would appear in the three countries if the trend cards have been built in the respective countries where the evaluations were done.

The trend cards were built in order to explain the potential relevant influences for new design solutions in the sector of shoes design. Fashion design is a main sector of influence for shoe design, hence an image of a person has been added to each ambience so the represented individuals reinforce the ambiences. It is certain that specific faces strongly influence emotional reaction. For example, the impact of cheerful in the emotional perception of the ambience 2, Pastel luxury, can come from the face of the character of this ambience. We investigated studies on the facial expression of emotions [42], but the lists we found are not precise enough to be useful in our context.

In conclusion, these findings imply that knowledge of the interested users values can help to predict emotional reactions to new design spaces like trend cards and the corresponding pallets.

From the initial knowledge of the users $\square$ behavioural values profiles, it is then possible to use these relations in order to build design rules linking the values space with the design elements. These relations can be chosen especially for the cases where the emotional reaction was linked to the preferences. For instance in the case of France, emotions related to the preferred trend cards were inspired, enthusiastic and serene and in a second time touched and stimulated.

In the Kansei Engineering system, appropriate harmonies of forms, textures and colours can be extracted from the trend cards corresponding to a specific ideal behavioural value profile. These harmonies can be used in the design solutions generation.

\subsection{Emotional evaluation in shoe design: generation and evaluation phase}

One of the aspects more relevant of the Kansei study is the comparison of results obtained for the different countries, so the discussion focuses on this issue. Results obtained from the different stages of the emotional evaluations allowed a comparison of differences between: (i) the structure and composition of the semantic spaces, (ii) users $\square$ perception in different countries and (iii) design rules. 
Title

\subsubsection{Structure and composition of the semantic spaces}

The qualitative comparison of the semantic spaces developed in the different countries has been carried out analysing and comparing the terms that integrate the semantic concepts in each country. A number of terms in the semantic universes of each country were found to be direct translations or to have very similar meanings to words in the other semantic universes. In some cases, factor analysis grouped together similar subsets of words, therefore in these cases, the different semantic concepts were directly comparable (for example the Spanish semantic axis Good Quality $\square$ Well Finished and the English axis Expensive-Good Quality).

In other occasions, the same word appeared on different Factors, hence the factors had different interpretations. For example the words refined, stylish and attractive form part of the Spanish Elegant-Well Dressed axis and the French Chic axis. In the UK the words tasteful, stylish and attractive form the Attractive-Tasteful axis, so the axis is not directly comparable with the Spanish or French ones because they also contain the concept of being elegant. In the UK the word Elegant would likely elicit a different reaction to the word Attractive or Tasteful.

Comparing the semantic spaces obtained in the three countries, it is found that in all countries the first component resulting from the factor analysis is related with the temporality of the product: the Modern/Innovative axis in Spain, the Contemporary / Original axis in UK and the Avant-garde axis in France. All these axes are related to the modernity and originality of the product. There is also a common perception component related to comfort.

\subsubsection{Users $\square$ perception in the different countries}

It has been found that the cultural differences between countries affect the perception elicited by the products so these geographical parameters have important implications for the footwear manufacturers. With the results provided by the methodology application, manufacturers can analyse and compare the image transmitted by their products in their different target markets, in order to define the product design. For example, the image of the product shown in Figure 9 is represented by its average in each one of the semantic axes in Spain and in UK. If we consider the Spanish axis Casual-sporting and the English axis Casual we see differences between countries, in the UK the product has been assessed as casual (positive) whereas in Spain it has obtained a negative evaluation.

Figure 6 Comparison of the product perception between countries (Spain and England)

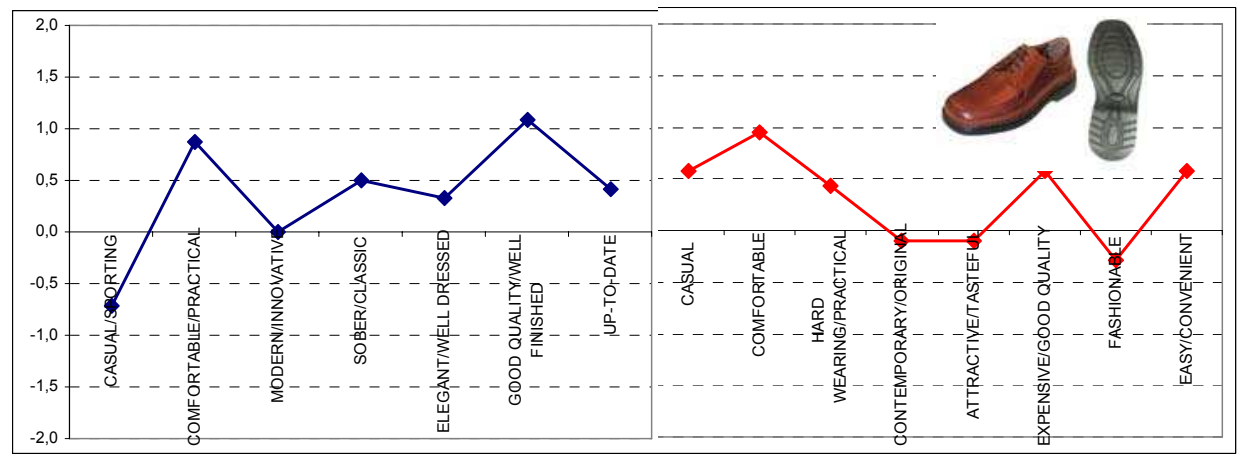


Author

a) Averages for the Spanish semantic axes

b) Averages for the English semantic axes

\subsubsection{Design rules}

The table 12 shows the total number of appearances of each design element in the set of design rules of each country.

Table 9 Number of occurrences for design factors in UK and Spain

\begin{tabular}{l|c|c}
\hline & \multicolumn{2}{|c}{ Number of occurrences } \\
\hline Design Factors & UK (8 axes) & Spain (7 axes) \\
\hline Top Profile & 3 & 2 \\
\hline Material & 5 & 6 \\
\hline Colour & 5 & 7 \\
\hline Fastening & 5 & 4 \\
\hline Sole Type & 5 & 7 \\
\hline Sole Material & 4 & 5 \\
\hline Seal Distribution & 6 & 7 \\
\hline Last Width & 5 & 6 \\
\hline Method of Application & 4 & 3 \\
\hline Collars & 4 & 6 \\
\hline
\end{tabular}

The seams distribution is one of the most important factors in defining the product perception both in UK and in Spain. The colour of the upper and the sole type are also important factors in the design.

The Spanish design rules were compared with the English design rules where it was believed the semantic axes were based on comparable words, for example, the Spanish model Casual-Sporting was compared with the English model for Casual. Both models contained the factors Material, Colour, Fastening, Sole Type, Seams distribution, Last Width, and Method of Application as significant predictors. There was found an agreement in direction and size of the odds ratios for all the common variables for both countries.

Table 10 Design element combinations most likely to elicit strong positive feeling on axis

\begin{tabular}{|c|c|c|}
\hline Design Factors & English axis Casual & Spanish Casual-Sporting \\
\hline \multicolumn{3}{|l|}{ Top Profile } \\
\hline Material & Suede & Suede \\
\hline Colour & Light & Light \\
\hline Fastening & Without & Without \\
\hline Sole Type & Soft / Flat & Soft / Flat \\
\hline Sole Material & & Synthetic \\
\hline Seams Distribution & Longitudinal/Sporty & Longitudinal /Sporty \\
\hline Last Width & Wide & Wide \\
\hline Method of Application & Cement / Moulded & Cement / Moulded \\
\hline Collars & & Bagged \\
\hline Largest Coefficient In Mode & $2^{\text {nd }}$ Largest $\mathrm{C}$ & $3^{\text {rd }}$ Larges \\
\hline
\end{tabular}




\subsection{Overall synthesis}

In this study a European investigation was done in three countries : Spain, France and England. This study was specific and original in the sense that it was applied at different steps of the product development process. User evaluation was done during the information phase in the early design process and in the evaluation phase at the end of the development process. In the first case, the corresponding design space was expressed through trend cards. In the second case the corresponding visual stimuli were real products on the market.

The hypothesis which led us to the experimental protocol aimed to demonstrate that (1) a European common approach studying the specific semantic structures in the three countries is an essential base for the generation of Kansei Technologies dedicated to European small companies in the field of shoes design; (2) the current databases in the KES can be enriched, (especially the input data), through Trend Analysis Methods, and (3) a complementary emotional assessment of the design stimuli is necessary to complete the results of the semantic differential. Value profiles can lead to specific semantic profiles and semantic profiles have a direct effect on the design elements.

\section{Conclusion}

An approach has been developed for the integration of users $\square$ expectancies as regards products on the basis of the Kansei Engineering framework, based on two different forms of user involvement in the design process: in the earliest stages of information gathering and in the latest stages of validation of product.

A relevant contribution is the implementation of a cross-country study which has provided results in different languages about the way users perceive and assess products and how this perception is related to the design components of the products.

However, results show that more robust models could be found by making advancements in characterising users and better defining the consumers $\square$ profile. Also, footwear is a complex product with design elements difficult to define and this lack of perfect definition of the products also affects the model quality.

In spite of all this, we feel that there are excellent opportunities for future applications of the methodology not only in footwear companies but also in other different sectors.

\subsection{Perspective for a KES}

The statistical analysis allowed the examination of links between user profiles, semantic structures and their corresponding emotional reactions as well as looking at the influence of specific design elements. Finally we recognize that there is a common core related to ideal values, to the felt emotions and to the corresponding semantic structures. These results confirm that the companies have to adopt a specific customization strategy according to these results. The continuation of the Kensys project involves the validation of the design rules in order to develop a useful tool for the different stages of the product process. Other perspectives of the Kensys project concern the reinforcement and deployment of a European assessment users panel to provide companies with emotional integration of their target customers. 
Author

\section{Acknowledgements}

Kensys Project is funded by the European Community under the Innovation \& SMEs $\square$ programme (IPS-2000) $\square$, VFP. This work was supported by the Institut Biomécanique de Valencia, the Laboratoire de Conception de Produits et Innovation (Société dEtudes et de Recherches 1Ecole Nationale Supérieure des Arts et Métiers), the Industrial Statistics Research Unit (University of Newcastle UPON TYNE), Pikolinos, Diedre Designs, Bjarni $₫$ B Boots and County Footwear.

\section{References}

1 Hutchins E., Cognitive artifacts, In Robert Wilson and Frank Keil (Eds), The MIT Encyclopedia of the Cognitive Sciences, Cambridege, MIT Press, 127, 2003

2 Norman, Emotional Design, Basic books, New York, 2004

3 Green WS, Jordan PW, Pleasure with products, beyond usability, new York 2002, Taylor and Francis

4 Bouchard, C. Lim, and Aoussat, A. (2003) Development of a Kansei Engineering System for industrial design - Identification of input data for KES, Journal of the Asian Design Conf. International vol.1 (ASSD), ISSN 1348-7817, 10 p.

5 Hsiao H, Huang HC. A neural network based approach for product form design. Design Studies, Vol 23, 2002, 67-84

6 Osgood C. E., The nature and measurement of the meaning, Semantic differential technique, a sourcebook, Chicago, Aldline Publishing Company,1969

7 Smets G.JF, Overbeeke CJ. Expressing tastes in packages, Design Studies, January Vol 16 n.3, 1995

8 Overbeeke CJ. Hekkert P., First Conference on Design \& Emotion, edited by. dr. ISBN 90-9013288-0. (C) 1999

9 Overbeeke, C.J., Locher, P. and Stappers, P.J (2000). Try to see it from the other side: A system for investigating 3-D form perception. In Proceedings of the Proceedings of the 16th congress of the International Association of Empirical Aesthetics, pp. 17, NY

10 Overbeeke, C.J., Djajadiningrat, J.P., Wensveen, S.A.G.and Hummels, C.C.M. (2000). Neglected aspects of HCI: Fun, beauty and bodily interaction.. In Proceedings of the OZCHI2000, Tutorial

11 Matthijs van Dijk, The brand is the product, the product is the brand, By KvD, The Netherlands \& Jeroen van Erp, Fabrique, The Netherlands

12 Battarbee K., and Mattelmäki T. Meaningful Product Relationships. In Proceedings of 3rd Conference of Design and Emotion. Loughborough. Forthcoming, 2002)

13 Schütte S., Designing feelings into products, Linköping Studies in Science and Technology, Thesis $\mathrm{N}^{\circ} .946,2002$

14 Petiot JF, Yannou B. measuring perceptions for a better comprehension, specification and assessment of product semantics, International Journal of Industrial Ergonomics, January Vol 33, pp507-525, 2004

15 Desmet P.M.A., To love and not to love, Why do products elicit mixed emotions, Proceedings of the first conferece on design and emotion, Nov. 1999, ISBN 909013288-0, pp 67-74 
Title

16 Desmet P.M.A., Hekkert P., When a car makes you smile : development and application to measure product emotions, Advances in consumer research, Vol. 27, $11-117,2000$

17 Spillers F., Emotion as a cognitive artifact and the design implication for products that are perceived as pleasurable, Website

18 Bouchard C, Mantelet F, Aoussat A, Trends integration in Kansei Engineering - A European approach, International Design Congress IASDR 2005

19 Lee SH, Modeling structure of Kansei : an analysis of how people appreciate art through a remote controlled robot, University of Tsukuba, 2002

20 Nagamashi M., Engineering as a powerful consumer-oriented technology for product development, Applied ergonomics, Vol 33, 2002, 289-294

21 Jindo T, Hirasago K, Nagamachi M. Development of a design support system for office chairs using 3D graphics, International Journal of Industrial Ergonomics, Volume 15, 1995, Pages 49-62

22 Jindo T, Hirasago K. Application studies to car interior of Kansei engineering, International Journal of Industrial Ergonomics, Volume 19, Issue 2, February 1997, Pages 105-114

23 Ishihara S, Ishihara K, Nagamashi M, Matsubara Y. An automatic builder for a Kansei engineering expert system using self-organizing neural networks, International Journal of Industrial Ergonomics, Volume 15, 1995, Pages 13-24

24 Ishihara S, Ishihara K, Nagamashi M, Matsubara Y. An analysis of Kansei structure on shoes using self-organizing neural networks, International Journal of Industrial Ergonomics, Volume 19, 1997, Pages 93-104

25 Tanoue C, Ishizaka K, Nagamachi M. Kansei Engineering : A study on perception of vehicle interior image, International Journal of Industrial Ergonomics, Volume 19, Issue 2, February 1997, Pages 115-128

26 Yang SM, Nagamashi M, Lee SY. Rule-based inference model for the Kansei Engineering System, International Journal of Industrial Ergonomics, Volume 24, 1999, Pages 459-471

27 Hsu SH, Chuang MC, Chang CC. A semantic differential study of designers and users product form perception, International Journal of Industrial Ergonomics, Volume 25, 2000, Pages 375-391

28 Chuang MC, Chang CC, Hsu SH. Perceptual factors underlying user preferences toward product form of mobile phones, International Journal of Industrial Ergonomics, Volume 27, Issue 4, April 2001, Pages 247-258

29 Suh MW, McCord M, Woo JL, Shalev I, Kim HB, Sensory (Kansei) Engineering of Aesthetics in Textile Fabrics, Code Number: F99-S2, This project was a Seed Project discontinued as of 4/30/00.) NC State

30 Lee SH, Harada A, Okazaki A. Modeling structure of Kansei : An analysis of how people appreciate art through a remote controlled robot, Art and Design Institute, University of Tsukuba, Graduate School of Comprehensive Human Science, University of Tsukuba, report of modelling the evaluation structure of Kansei 2001, p.203

31 Yukihiro Matsubara, John R. Wilson and Mitsuo Nagamachi. (1998) Comparative study of Kansei engineering analysis between Japan and BRITAIN. Proceedings of the 6th International Conference on Human Aspects of Advanced Manufacturing: Agility and Hybrid Automation, Hong Kong, 5-8 July 1998.

32 Maekawa Y, Nagamachi M (1997). Presentation system of forming into desirable shape and feeling of women $\triangle \mathrm{s}$ breast. Kansei engineering-I: Proc first Japan-Korea Sympos on Kansei Engineering -Consumer- Oriented product development technology. Kaibundo, pag. 37-43 
Author

33 Eckert C, Stacey M. Sources of inspiration : a language of design, Design studies, Vol 21 Number 5, September 2000, Pages 523-538

34 Ansburg PI, Hill K, Creative and analytric thinkers differ in their use of attentional ressources, PAID, 2002

35 Kuroda K, Hagiwara M. An image retrieval system by impression words and specific objects names - IRIS, Neurocomputing Vol 43, 2002, 259-276

36 Bouchard C, Christofol H, Roussel B, Aoussat A, Identification and integration of product design trends, International Conference on Engineering Design, Munich, August 24-26, 1999

37 Christofol H., Roussel B., Bouchard C., Aoussat A., Analogue reasoning, a foundation of the technologic, stylistic, and ergonomic creativity, Congrès International de Génie Industriel GI5, Montréal- 2000

38 Rokeach M., The nature of human values, New York, The free press, 1973

39 Mantelet F., International Journal of Industrial Ergonomics, in process

40 Lang, P. J., Bradley, M. M., \& Cuthbert B. N. (1997). International affective picture system : Technical manual and affective ratings. Gainseville, FL : The Center for Research in Psychophysiology, University of Florida.

41 Lang, P. J., Greenwald, M. K., Bradley, M. M., \& Hamm, A. O. (1993). Looking at pictures : affective, facial, visceral, and behavioral reactions. Psychophysiology, 30, 261-273

42 Ekman P, Facial signs : facts, fantasies and possibilities, in T. Sebeok (Ed.), Sight, Sound and Sense. Bloomington : Indiana University Press.

43 Ekman, P. \& Friesen, W. V. (1978). Facial action coding system: A technique for the measurement of facial movement. Palo Alto, Calif.: Consulting Psychologists Press.

44 Ekman, P. \& Friesen, W. (1986). A new pan-cultural facial expression of emotion. Motivation and Emotion, 10, 159-168.

45 Cox, D.R. (1966). Some procedures associated with the logistic qualitative reaction curve. Research Papers in Statistics, 55-71. Wiley, New York.

46 Day, N.E., Kerridge, D.F. (1967). A general maximum likelihood discriminant. Biometrics, 23, 313-323.

47 Anderson, J.A.(1972). Separate Sample Logistic Discrimination, Biometrika, 59, 1, 19-35.

48 Anderson, J.A. (1982). Logistic Discrimination, Ed. P.R. Krishnaiah and L.N.Kannal. Handbook of Statistics, Classification, Pattern Recognition and Reduction in Dimensionality. 2, 169-191. North Holland

49 Anderson, J.A., Philips, P.R. (1981). Regression, discrimination and measurement models for ordered categorical variables. Applied Statistics, 30, 1, 22-31.

50 Cole T.J., Manly, C.J., Thornton, A.J., Fowler, M.A., Hewson, P.H. (1991). A scoring system to quantify illness in babies under 6 months of age. Journal of the Royal Statistics Society, A, 154, 2, 287-304. 